\title{
Penentuan Ion Aluminium (III) Dalam Air Tanah Dengan Metode Ekstraksi Fasa Padat
}

Erdawati

Jurusan Kimia, FMIPA Universitas Negeri Jakarta, Jl pemuda No 10, Rawamangun 13220, Jakarta ,Indonesia

\begin{abstract}
Abstrak
Kandungan ion Aluminium (III) dalam air tanah dipekatkan dengan metode ekstraksi fasa padat menggunakan adsorben nanoemulsi kitosan yang dimodifikasi dengan Alizarin, kemudian kompleks Al-alizarin dianalisa dengan menggunakan spektrofotometer pada panjang gelombang maksimum $540 \mathrm{~nm}$. Beberapa parameter untuk menentukan kondisi optimum proses pemekatan seperti $\mathrm{pH}$, volume, berat adsorben dan laju alir sampel divariasikan pada berbagai kondisi. Hasil penelitian menunjukkan bahwa $150 \mathrm{ml}$ larutan ion aluminium (III) dengan konsentrasi $1 \mu \mathrm{g} / \mathrm{mL}$ pada pH5.5 dan lajur alir 1,5 mL/menit memberikan hasil perolehan kembali 95\%. Presisi dan limit deteksi metode pemekatan terhadap 10 buah sampel uji memberikan nilai akurasi dan presisi 95\% dengan limit deteksi 0,13 $\mathrm{\mu g} / \mathrm{mL}$
\end{abstract}

Kata kunci : Aluminium, air tanah, ekstraksi fasa padat,nanodispersi kitosan, alizarin

\section{Pendahuluan}

Air tanah adalah air yang terdapat dalam lapisan tanah. Air tanah berasal dari air hujan yang meresap ke dalam tanah. Pada proses peresapan tersebut, lapisan lapisan tanah berfungsi sebagai penyaring, sehingga air tanah lebih jernih dibanding dengan air permukaan. Oleh karena itu air tanah banyak digunakan oleh masyarakat sebagai sumber air minum dan keperluan lainnya. Air tanah yang banyak mengandung ion aluminium dapat menyebabkan penyakit Alzheimer dan kerusakan organ tubuh. Selain itu air yang tercemar dengan ion aluminium dapat mempercepat terjadinya korosi pada pipa saluran air. Untuk menghindari terjadinya kerusakan akibat ion aluminium, pemerintah telah menetapkan baku mutu ion aluminium untuk air minum, air untuk pertanian dan baku mutu untuk air limbah.

Berbagai metode dan teknik yang dapat digunakan untuk menentukan kandungan ion aluminium dalam air di antaranya titrasi, penukar ion dan dengan instrumen spektrofotometer UV Vis. Metode dan teknik yang paling sering dilakukan adalah ICP-OES, ICP-MS, GFAAS dan FAAS. FAAS merupakan metode yang sederhana dan biaya operasionalnya murah, tetapi sensitifitasnya rendah. Oleh sebab itu untuk sampel yang kandungan ion logamnya kecil, sebelum dianalisa perlu dipekatkan

Metode ekstraksi fase padat (SPE) merupakan metode yang banyak digunakan sebagai teknik untuk pemekatan. Teknik tersebut memberikan keuntungan seperti waktu ekstraksi yang pendek, biaya rendah, tingginya faktor pemekatan dan pemulihan, dan memerlukan sedikit pelarut sebagai eluen. Suparna et al [1] menggunakan kitosan dan derivat kitosan untuk memekatkan ion ion logam tanah jarang. Hasil penelitiannya menujukkan bahwa kapasitas ekstraksi kitosan yang diikat silang dengan glutaraldehid lebih baik dibandingkan dengan kitosan. Kitosan yang dimodifikasi dengan di-2-propanolamin digunakan untuk memekatkan germanium dalam air pipa, air laut dan air sungai. Hasil analisa dengan menggunakan ICP menunjukkan bahwa konsentrasi germanium berkisar dari 0.011 to $0.022 \mu \mathrm{g} \mathrm{L-1.} \mathrm{[2].} \mathrm{Untuk} \mathrm{menguji}$ kesensitifan dan selektifitas kolum C18, Alaa[3] mengalirkan larutan komplek kobalt-5-(2benzothiazolylazo)-8-hydroxyquinolin

(CoBTAHQ) dan kemudian dielusi dengan isopentil alkohol. Konsentrasi ion cobalt diukur dengan menggunakan spektrofotometer UV Vis pada 
panjang gelombang $658 \mathrm{~nm}$. Hasil uji terhadap 11 buah sampel menunjukkan nilai simpangan baku 1,37 \% dan limit deteksi 3,1- 9,7 ng/ml.

Carla et al[4] menggunakan metode ekstraksi fasa padat untuk memekatkan kandungan kaffein dan asam organik dalam kopi Robusta dan kopi Arabika menggunakan kolum C18. Hasil analisa menunjukkan bahwa kandungan asam organik dalam kopi tergantung pada geografi tempat tumbuh kopi dan juga jenis kopi. Saied Saeed et al[5] juga menggunakan kolum C 18 untuk memekatkan ion plumbum(II) dalam gula dengan metode ekstraksi fasa padat. Silika gel yang dimodifikasi dengan kurkumin digunakan oleh Xiangbing et al [6] sebagai sorben untuk memekatkan ion logam dalam sampel biologi dan air permukaan dan selanjutnya dianalisa dengan menggunakan ICPOES. Hasil analisa menunjukkan bahwa analisa dengan ICP OES mempunyai batas deteksi masing masing untuk ion $\mathrm{Cu}(\mathrm{II}), \mathrm{Fe}$ (III) dan $\mathrm{Zn}(\mathrm{II})$, adalah $0,12,0.15$ and $0.40 \mathrm{ng} / \mathrm{mL}$ dan simpangan baku lebih rendah dari $3 \%$ untuk $n=$ 5. Metode pemekatan dan metodse analisa divalidasi dengan menggunakan material standar.

Pengaruh jumlah volume eluen, jenis eluen, dan $\mathrm{pH}$ eluen pada ekstraksi fasa padat dengan nanokarbon multi wall telah dikaji oleh Mustafa [7] untuk memekatkan ion kuprum(II). Hasil penelitiannya menunjukkan bahwa kondisi optimal diperoleh jika pH eluen 5-7, dan eluen yang digunakan asam nitrat $2 \mathrm{M}$ dengan laju alir $2 \mathrm{ml} /$ menit.

Nanoemulsi merupakan salah satu adsorben yang menjadi perhatian para peneliti, karena mempunyai permukaan yang luas, kapasitas adsorpsi besar, dan biaya operasional jauh lebih rendah. Nanoemulsi kitosan salah satu nanosorben yang telah digunakan untuk mengadsorpsi zat warna [8-9]

Nanosorben yang dilapis dengan reagent, senyawa organik dan polimer merupakan metode yang banyak digunakan untuk meningkatkan daya adsorpsi. Nanomagnetik
$\mathrm{Fe}_{3} \mathrm{O}_{4}$ yang dilapis dengan glukosa dan kitosan merupakan adsorben untuk kolum esktraksi fasa padat yang dapat memekatkan senyawa phenol, telah dilaporlan oleh Yingying[10] Sorben nanomagnetik $\mathrm{Fe}_{3} \mathrm{O}_{4}$-glukosa-kitosan mempunyai ukuran $400 \mathrm{~nm}$ dan magnetisasi 60,22 emu g-1.Hasil rekoveri untuk ekstraks biphneol sebesar 99,4-102,69\% menunjukkan bahwa nanomagnetik merupakan nanosorben yang yang layak digunakan untuk memekatkan ion ion logam. Pada penelitian ini nanoemulsi kitosan yang dilapis dengan Alizarin digunakan untuk memekatkan ion aluminium dalam air tanah.

\section{Percobaan}

Alat yang diperlukan alat gelas, kolum nanomagnetik kitosan, $\mathrm{pH}$ meter dan AAS

Bahan yang diperlukan : Alizarin, aluminium nitrat, akuadest, etanol, larutan buffer, $\mathrm{HCL}$ , $\mathrm{HNO}_{3}$, kitosan , STPP

\subsection{Pembuatan nanodispersi kitosan}

Kedalam $500 \mathrm{ml}$ larutan asam asetat 0.5\% dilarutkan kitosan sebanyak 4 gram. Larutan diaduk dan dibiarkan selama 24 jam sampai semua kitosan larut. Pada gelas kimia yang lain 6 gram STPP dilarutkan dalam $500 \mathrm{ml}$ akuadest. Kedalam $25 \mathrm{ml}$ larutan kitosan ditambahkan larutan STPP dengan volume mulai dari 20, 25, 35 dan 40 ml.Larutan STPP ditambahkan sedikit demi sedikit kedalam larutan kitosan sambil diaduk selama 60 menit sehingga terbentuk nanoemulsi kitosan

\subsection{Pembuatan nanoemulsi kitosan-Alizarin .}

4 gram nanoemulsi kitosan dicampur dengan 1gram Alizarin, dilarutkan dengan $5 \mathrm{ml}$ dimetilsulfoksida dan $70 \mathrm{ml}$ metanol, diaduk selama 8 jam. Kemudian keringkan pada suhu $70{ }^{0} \mathrm{C}$ selama $7 \mathrm{jam}$ 


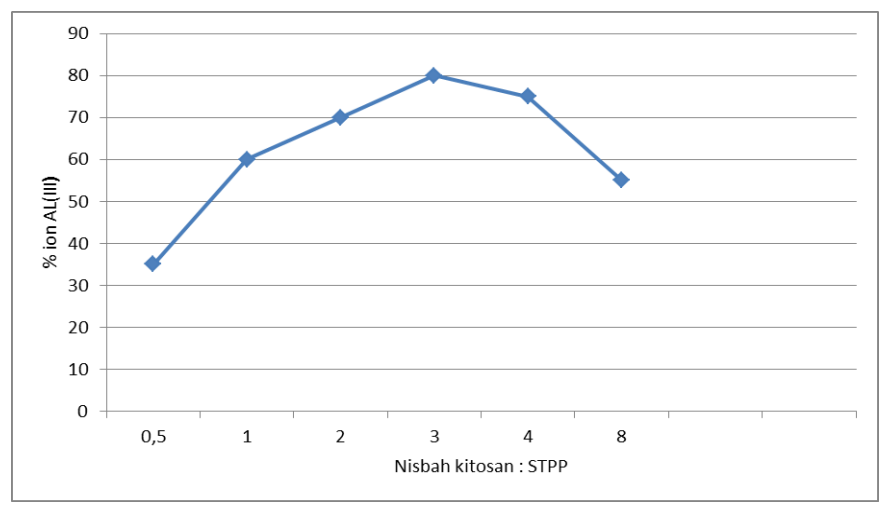

Gambar 1 pengaruh nisbah kitosan - STPP terhadap \% penyerapan Ion AI(III)

\subsection{Pra kondisi kolum}

Ke dalam mikrokolum (ukuran $10 \mathrm{~cm}$ x 1,5 cm) dimasukkan nanodispersi kitosan-Alizarin setinggi $4,5 \mathrm{~cm}$. Kemudian dicuci dengan $5 \mathrm{ml}$ etanol, $10 \mathrm{ml}$ akuades, dilanjutkan dengan $5 \mathrm{ml}$ $\mathrm{HCl} 1 \mathrm{M}$, dan terakhir dengan $10 \mathrm{ml}$ akuadest.Kolum dikeringkan dengan cara melewatkan udara selama beberapa menit. Panaskan kolum pada suhu $60^{\circ} \mathrm{C}$ selama 30 menit, agar pelarut menguap. Untuk memastikan kolum sudah kering, alirkan lagi udara selama beberapa menit.

\subsection{Pemekatan ion aluminium}

Larutan ion $\mathrm{Al}(\mathrm{III})$ dengan berbagai konsentrasi, berbagai $\mathrm{pH}$ dialirkan kedalam kolum, dengan laju alir $1 \mathrm{ml} /$ menit. ion $\mathrm{Al}(\mathrm{III})$ yang tertahan dalam kolum dielusi dengan $5 \mathrm{ml}$ asam nitrat $3 \mathrm{M}$. Kandungan ion Al(III) dalam effluent diukur dengan menggunakan AAS

\subsection{Pengaruh komposisi nanoemulsi kitosan terhadap penyerapan ion Al(III)}

Gambar 1 menunjukkan pengaruh komposisi nanoemulsi kitosan terhadap persentase ion $\mathrm{Al}($ III) yang teradsorpsi. Adsorpsi ion $\mathrm{Al}(\mathrm{III})$ dengan nanoemulsi kitosan pada berbagai komposisi dilakukan pada $\mathrm{pH} 5.0$ dan pada suhu kamar. Dari Gambar 1 dapat dilihat pada nisbah kitosan terhadap STPP $3: 1$, ion Al(III) yang teradsorpsi sebesar $80 \%$, sementara jika nisbah kitosan terhadap STPP sebesar $1: 1$ persentase Ion $\mathrm{Al}(\mathrm{III})$ yang teradsorpsi hanya $35 \%$.

\subsection{Pengaruh Jumlah Alizarin}

Pengaruh jumlah Alizarin yang diperlukan untuk mengadsopsi ion AI(III) dilakukan dengan menggunakan Alizarin pada berbagai jumlah mulai dari $20 \mathrm{mg}$ sampai $100 \mathrm{mg}$. Hasil percoban ditunjukkan pada Gambar 2.

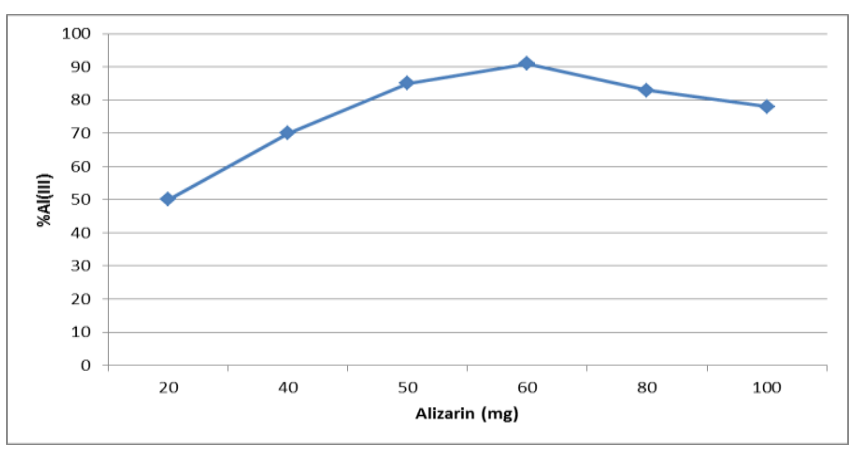

Gambar 2 pengaruh Alizarin (mg) terhadap \% penyerapan Ion AI(III) 
Dari gambar 2 dapat dilihat bahwa diperlukan 50 mg Alizarin untuk mengadsorpsi $100 \mu \mathrm{g}$ ion $\mathrm{Al}(\mathrm{III})$ pada $\mathrm{pH}$ 5.5. Jika berat Alizarin semakin bertambah, kemungkinan terbentuk kompleks Al-Alizarin yang bermuatan yang larut dalam air

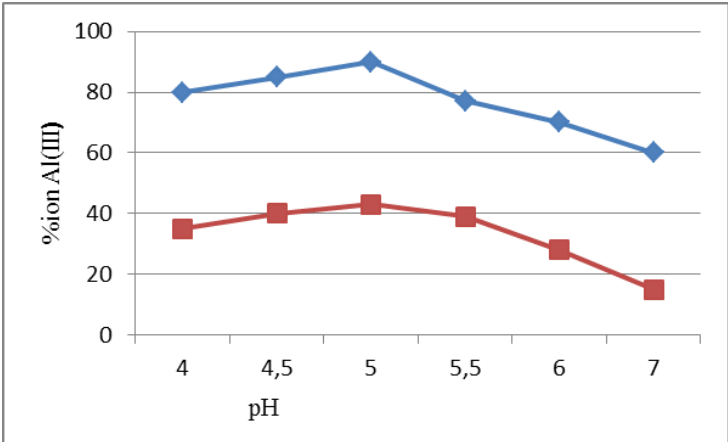

Gambar 3. Pengaruh pH terhadap \% penyerapan Ion $\mathrm{Al}(\mathrm{III})$ olehkitosan dan nanoemulsi kitosanAlizarin

\subsection{Pengaruh pH Ion Al(III)}

Adsorpsi Ion Al(III) oleh kitosan dan nanoemulsi kitosan pada berbagai $\mathrm{pH}$, dengan konsentrasi Ion AI(III) $100 \mu \mathrm{g}$ ditunjukkan pada gambar 2. Dari gambar 2 dapat dilihat bahwa kemampuan nanoemulsi kitosan menyerap Ion $\mathrm{Al}(\mathrm{III})$ lebih besar dibanding kitosan dan kedua adsorben menyerap Ion $\mathrm{Al}(\mathrm{III})$ pada $\mathrm{pH} 4.0$ sampai 5.0. $\mathrm{pH}$ larutan ion aluminium mempengaruhi jumlah ion yang diadsorpsi oleh nanoemulsi kitosan-alizarin.
Pada suasana asam, ion $\mathrm{H}^{+}$membentuk khelat dengan gugus gugus aktif dari alizarin, sebaliknya pada suasanan basa ion aluminium menjadi ion hidroksi aluminium dan mengendap sebagai senyawa hidroksida.

\subsection{Pengaruh berat adsorben}

Sejumlah adsorben mulai dari 20 sampai $100 \mathrm{mg}$ digunakan untuk memastikan jumlah adosrben yang diperlukan untuk mengadsorpsi $100 \mu \mathrm{g}$ ion $\mathrm{Al}(\mathrm{III})$. Gambar 4 menunjukkan hasil percobaan. Dari gambar 4 tersebut dapat dilihat bahwa makin banyakadsorben yang digunakan makiin banyak ion $\mathrm{Al}(\mathrm{III})$ yang teradsorpsi. Jumlah adsorben yang efektif untuk mengadsorpsi $100 \mu \mathrm{g}$ ion $\mathrm{Al}(\mathrm{III})$ adalah $50 \mathrm{mg}$.

\subsection{Laju Alir Larutan Ion Al(III)}

Laju alir Ion Al(III) merupakan parameter yang perlu diperhatikan, karena waktu retensi Ion $\mathrm{Al}(\mathrm{III})$ dalam kolum tergantung pada laju reaksi. Gambar 5 menunjukkan pengaruh laju alir sampel terhadap \% Ion Al(III) yang tertahan dalam kolum. Laju alir optimum diperoleh pada kondisi $1 \mathrm{ml} /$ menit

\section{6 . Pengaruh Volume Ion AI(III)}

Ion $\mathrm{Al}(\mathrm{III})$ dengan konsentrasi $1 \mu \mathrm{g} / \mathrm{mL}$ dalirkan dengan laju 1,5 ml/menit sebanyak 50 $\mathrm{ml}$ sampai $300 \mathrm{ml}$. Ion $\mathrm{Al}(\mathrm{III})$ yang tertahan dalam kolum kemudian dielusi.

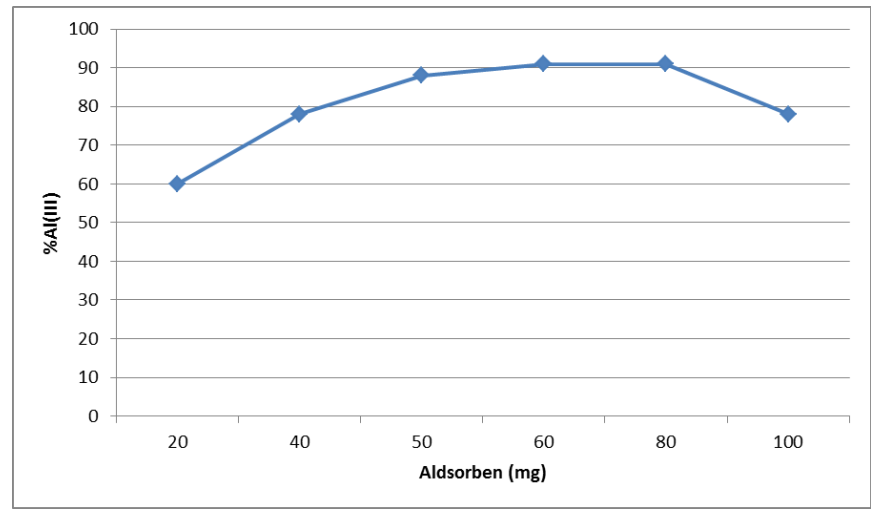

Gambar 4 Pengaruh konsentrasi adsorben terhadap ion $\mathrm{Al}(\mathrm{III})$ yang teradsorpsi 


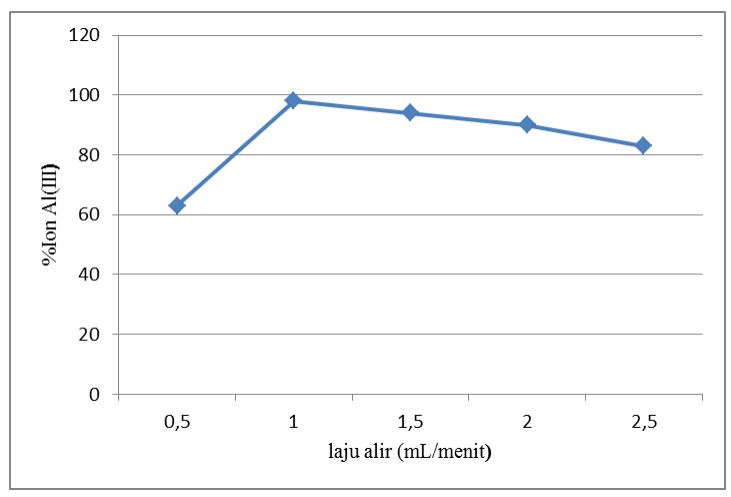

Gambar 5 pengaruh laju alir terhadap persentase perolehan kembali ion aluminium

Persentase lon $\mathrm{Al}(\mathrm{III})$ yang tertahan dalam kolum dipengaruhi oleh oleh volume larutan Ion AI(III) seperti yang ditunjukkan pada Gambar 6 berikut. Dari Gambar 6 dapat dilihat bahwa semakin banyak volume yang dialirkan semakin sedikit Ion $\mathrm{Al}$ (III) yang dapat diadsorpsi oleh nanoemulsi kitosan. Hal ini disebabkan jika volume Ion AI(III) semakin banyak nanoemulsi tidak mampu mengadsorpsi Ion Al(III), karena gugus aktifnya sudah jenuh .

\subsection{Pengaruh jenis dan volume eluen}

Untuk mengeluasi ion Al yang teradospsi pada adsorben digunakan berbagai jenis eluen dengan berbagai konsentrasi. Hasil percobaan ditunjukkan pada tabel 1 di bawah ini

Tabel 1. Pengaruh jenis eluen terhadap \% perolehan kembali ion $\mathrm{Al}(\mathrm{III})$

\begin{tabular}{|l|l|c|}
\hline No & \multicolumn{1}{|c|}{ Eluen } & \% ion $\mathrm{Al}(\mathrm{III})$ \\
\hline 1 & $\mathrm{HCL} 1 \mathrm{M}$ & 41 \\
\hline 2 & $\mathrm{HCl} 2 \mathrm{M}$ & 68 \\
\hline 3 & $\mathrm{HNO}_{3} 1 \mathrm{M}$ & 54 \\
\hline 4 & $\mathrm{HNO}_{3} 2 \mathrm{M}$ & 75 \\
\hline 5 & $\mathrm{HNO}_{3} 3 \mathrm{M}$ & 91 \\
\hline
\end{tabular}

Eluen yang paling efektif untuk mengeluasi Ion $\mathrm{Al}(\mathrm{III})$ adalah $\mathrm{HNO}_{3} 3 \mathrm{M}$ yang mampu mengelusi seluruh ion Al(III) yang teradsorpsi pada adsorben nanoemulsi kitosan-Alizarin.

\section{8 . Analisa Presisi dan Limit Deteksi}

Pada kondisi optimum dilakukan uji presisi dan limitdeteksi dengan menggunakan 10 buah sampel .Hasil uji menunjukkan nilai deteksi limit untuk Ion Al(III) dengan konsentrasi $1 \mu \mathrm{g} / \mathrm{mL}$ sebesar $0,12 \mu \mathrm{g} / \mathrm{mL}$ dengan simpangan baku $3 \%$

\subsection{Analisa Perolehan kembali}

Untukmenguji performance dari metode yang digunakan dilakukan uji perolehan kembali untuk memverifikasi ahsil analisa yang diperoleh setelah ditambahkan sejumlah analit kedalam sampel air tanah . hasil percobaan ditunjukkan pada tabel 2. Hasil percobaan menunjukkan bahwa hasil perolehan kembali lebih kurang 94\% yang bermakna bahwa metode SPE yang digunakan memberikan hasil yang akurat.

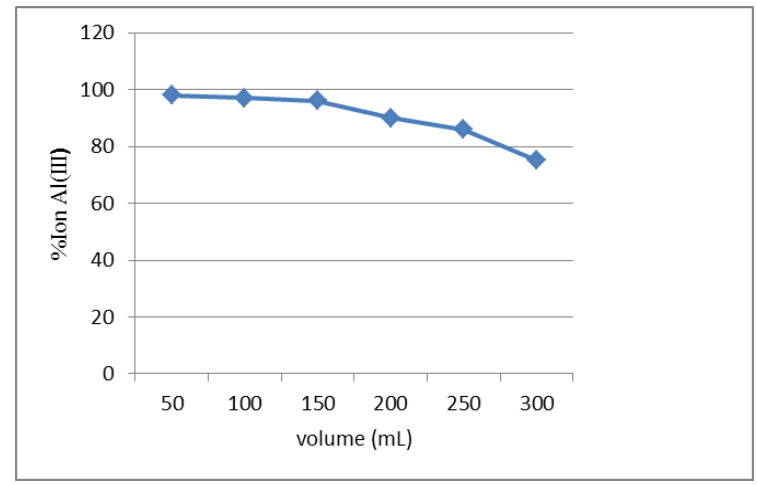

Gambar 6 pengaruh volume sampel terhadap persentase perolehan kembali

Tabel 2. Analisa hasil perolehan

\begin{tabular}{|l|l|l|l|l|}
\hline No & $\begin{array}{l}\text { Penambahan } \\
\text { ion } \mathrm{Al}(\mu \mathrm{gL}-1)\end{array}$ & $\begin{array}{l}\text { Perolehan } \\
\mathrm{Al}(\mathrm{III}) \\
(\mu \mathrm{gL}-1)\end{array}$ & $\begin{array}{l}\text { RS } \\
\mathrm{D}\end{array}$ & $\begin{array}{l}\text { Perol } \\
\text { ehan } \\
\text { kemb } \\
\text { ali }\end{array}$ \\
\hline 1 & 0 & 52 & 0.8 & - \\
\hline 2 & 50 & 100 & 1.2 & 92 \\
\hline 3 & 75 & 116 & 1.1 & 90 \\
\hline 4 & 100 & 154 & 1.2 & 100 \\
\hline
\end{tabular}

\section{Kesimpulan}

Kolum nanoemulsi kitosan yang dimodifikasi dengan alizarin digunakan untuk menentukan kandungan ion aluminum dalam air tanah. Hasil uji menunjukkan bahwa pada konsentrasi larutan sampel $1 \mu \mathrm{g} / \mathrm{mL}$ dengan $\mathrm{pH}$, dialirkan 
sebanyak $150 \mathrm{ml}$ dan laju alir 1,5 ml/menit, ion aluminium teradorpsi lebih dari $95 \%$. Uji analisa presisi dan limit deteksi terhadap 10 buah sampel menghasilkan nilai simpangan baku $3 \%$ dengan limit deteksi sebesar $0,12 \mu \mathrm{g} / \mathrm{mL}$

\section{Daftar Pustaka}

[1] Suparna Dutta, P.K. Mohapatra, S.P. Ramnani, S. Sabharwal, Arabinda K. Das, V.K. Manchanda.2008. Use of chitosan derivatives as solid phase extractors for metal ions. De salination 232 : 234-242

[2] Akhmad Sabarudin, Tomonari Umemura, Shoji Motomizu.2011. Chitosan functionalized with di-2-propanolamine: Its application as solid phase extractant for the determination of germanium in water samples by ICP-MS.Microchemical Journal 99 : 34-39.

[3] Alaa S. Amin .2011. Study on the solid phase extraction and spectrophotometric determination of cobalt with5-(2-benzothiazolylazo)- 8-hydroxyquinolene. Arabian Journal of Chemistry

[4] Carla Isabel Rodrigues, Liliana Marta, Rodrigo Maia, Marco Miranda,Miguel Ribeirinhob, Cristina Ma' guas.2011.Application of solid-phase extraction to brewed coffee caffeine and organic acid determination by UV/HPLC. American Journal of Analytical Chemistry, 2 : 626-631

[5] Saied Saeed Hosseiny Davarani, Neda Sheijooni-Fumani, Amin Morteza Najarian, Mohammad-Ali Tabatabaei, Siavash Vahidi.2011. Preconcentration of Lead in Sugar Samples by Solid Phase Extraction and Its Determination by Flame Atomic Absorption Spectrometry American Journal of Analytical Chemistry, 2: 626- 631

[6] Xiangbing Zhu, Xijun Chang, Yuemei Cui, Xiaojun Zou, Dong Yang, ZhengHu.2007.

[7] Solid-phase extraction of trace $\mathrm{Cu}$ (II) Fe(III) and Zn(II) with silica gel modified with curcumin from biological andnatural water samples by ICP-OES. Microchemical Journal 86 : 189-194

[8] Mustafa Soylak, Omer Ercan.2009. Selective separation and preconcentration of copper(II) in environmental samples by the solid phase extraction on multi-walled carbon nanotubes. Journal of Hazardous materials 165 : 1527- 1531.

[9] Momenzadeh.H, A.R. Tehrani-Bagha, A. Khosravi, K. Gharanjig, K. Holmberg .2011. Reactive dye removal from wastewater using a chitosan nanodispersion. Desalination 271 : 225-230

[10] Hu,Z.G; J. Zhang, W.L. Chan, Y.S. Szeto.2006.The sorption of acid dye onto chitosan nano particles, Polymer 47 : 5838-5842.

[11] Yingying Geng, Mingyu Ding, Hui Chen, Hai-Fang Li, Jin-Ming Lin.2011.

[12] Preparation of hydrophilic carbon-functionalized magnetic microspheres coated with chitosan and application in solid-phase extraction of bisphenol $A$ in aqueous samples. 